\title{
MENENTUKAN INVERS MOORE-PENROSE DENGAN METODE BEN NOBLE
}

\author{
ANNISA MAULA ZAKIYA, YANITA, NOVA NOLIZA BAKAR \\ Jurusan Matematika, \\ Fakultas Matematika dan Ilmu Pengetahuan Alam, Universitas Andalas, \\ Kampus UNAND Limau Manis Padang, Indonesia, \\ email: annisa.amaza@gmail.com
}

\begin{abstract}
Abstak. Tulisan ini membahas tentang metode penghitungan invers Moore-Penrose dari matriks $A \in \mathbb{C}^{m \times n}$ dengan $\operatorname{rank}(A)>0$. Metode yang digunakan adalah metode BenNoble. Teori yang diperlukan untuk penghitungan invers Moore-Penrose menggunakan metode Ben-Noble adalah faktorisasi full rank dan partisi matriks.

Kata Kunci: Invers Moore-Penrose, Faktorisasi Full Rank, Matriks Partisi
\end{abstract}

\section{Pendahuluan}

Konsep suatu matriks sangat berguna dalam menyelesaikan permasalahan ilmu matematika, salah satunya adalah penyelesaian menggunakan invers matriks. Invers matriks dapat digunakan untuk menyelesaikan sistem persamaan linear. Misalkan suatu matriks $A$ berukuran $n \times n$ dengan determinan $A$ tidak nol $(\operatorname{det}(A) \neq 0)$, maka $A$ dikatakan memiliki invers.

Pada tahun 1920, E. H Moore mendeskripsikan salah satu jenis invers matriks, yaitu generalisasi invers. Generalisasi invers suatu matriks $A$ dapat ditentukan jika $A$ berukuran $m \times n$ atau $\operatorname{det}(A)=0$. Selanjutnya Roger Penrose menyempurnakan generalisasi invers yang dikemukakan oleh Moore, inilah yang disebut invers Moore-Penrose. Seiring berkembangnya ilmu matematika, maka untuk menentukan invers Moore-Penrose ini terdapat beberapa cara, diantaranya dengan menggunakan metode Zlobec dan MacDuffe. Terdapat juga metode lain, yaitu metode yang diberikan oleh Ben-Noble dengan menggunakan partisi matriks. Pada tulisan ini penulis akan membahas penghitungan invers moore-penrose dengan metode BenNoble.

\section{Tinjauan Teori}

\subsection{Matriks dan Operasi Matriks}

Definisi 2.1. [1] Jika A dan B adalah matriks-matriks dengan ukuran yang sama, maka jumlah $A+B$ adalah matriks yang diperoleh dengan menjumlahkan entri-entri pada $B$ dengan entri-entri yang bersesuaian pada $A$ dan selisih $A-B$ adalah matriks yang diperoleh dengan mengurangkan entri-entri pada $A$ dengan entri-entri yang 
bersesuaian pada B. Matriks dengan ukuran yang berbeda tidak dapat dijumlahkan atau dikurangkan.

Definisi 2.2. [1] Jika A adalah matriks sebarang dan c adalah skalar sebarang, maka hasilkali-nya $c A$ adalah matriks yang diperoleh dari perkalian setiap entri pada matriks A dengan bilangan c. Matriks cA disebut kelipatan skalar dari A.

Definisi 2.3. [1] Jika $A$ adalah matriks $m \times r$ dan $B$ adalah matriks $r \times n$ maka hasilkali $A B$ adalah matriks $m \times n$ yang entri-entrinya ditentukan sebagai berikut. Untuk mencari entri pada baris i dan kolom $j$ dari $A B$, pisahkan baris i dari matriks $A$ dan kolom $j$ dari matriks B. Kalikan entri-entri yang bersesuaian dari baris dan kolom tersebut dan kemudian jumlahkan hasil yang diperoleh.

Definisi 2.4. [1] Jika A adalah matriks $m \times n$, maka transpos dari A di-nyatakan dengan $A^{T}$, didefinisikan sebagai matriks $n \times m$ yang didapatkan dengan mempertukarkan baris-baris dan kolom-kolom dari $A$, sehingga kolom pertama dari $A^{T}$ adalah baris pertama dari $A$, kolom kedua dari $A^{T}$ adalah baris kedua dari $A$, dan seterusnya.

Misal $A=\left(a_{i j}\right)$ dengan entri-entri $\in \mathbb{C}$, maka $\bar{A}$ adalah matriks konjugat dari $A$ yang didefinisikan sebagai $\bar{A}=\left(\overline{a_{i j}}\right)$ dengan $\overline{a_{i j}}$ adalah konjugat dari $a_{i j}$. Konjugat transpos suatu matriks dinotasikan dengan $A^{*}$, didefinisikan sebagai $A^{*}=\bar{A}^{T}$.

Terdapat beberapa sifat yang terkait dengan konjugat transpos dari suatu matriks, yaitu jika ukuran matriks $A, B, I$ dan $\mathbb{O}$ sedemikian rupa sehingga operasi berikut dapat dilakukan serta $k \in \mathbb{C}$, maka :

(1) $\left(A^{*}\right)^{*}=A$.

(2) $(A+B)^{*}=A^{*}+B^{*}$ dan $(A-B)^{*}=A^{*}-B^{*}$.

(3) $(k A)^{*}=\bar{k} A^{*}$.

(4) $(A B)^{*}=B^{*} A^{*}$.

(5) $\left(I_{n}\right)^{*}=I_{n}$.

(6) $\mathbb{O}^{*}=\mathbb{O}$.

Teorema berikut memuat sifat-sifat utama dari operasi transpos.

Teorema 2.5. [1] Jika ukuran matriks A, B sedemikian rupa sehingga operasioperasi berikut dapat dilakukan, maka :

(1) $\left(A^{T}\right)^{T}=A$.

(2) $(A+B)^{T}=A^{T}+B^{T}$ dan $(A-B)^{T}=A^{T}-B^{T}$.

(3) $(k A)^{T}=k A^{T}$, dengan $k$ adalah skalar sebarang.

(4) $(A B)^{T}=B^{T} A^{T}$.

Definisi 2.6. [1] Permutasi dari himpunan bilangan bulat atau integer $\{1,2, \cdots, n\}$ adalah susunan integer-integer ini menurut suatu aturan tanpa adanya penghilangan atau pengulangan.

Definisi 2.7. [7] Misalkan $\sigma$ adalah permutasi. Didefinisikan matriks permutasi $P(\sigma)=\left[\delta_{i, \sigma(j)}\right]$ dimana $\delta_{i, \sigma(j)}$ bernilai 1 jika $i=\sigma(j)$, dan 0 jika $i \neq \sigma(j)$. 


\subsection{Matriks Partisi}

Sebuah matriks dapat dibagi atau dipartisi menjadi beberapa matriks yang lebih kecil dengan cara menyisipkan garis-garis horizontal dan vertikal di antara baris dan kolom yang diinginkan. Misalkan $A=\left[a_{i j}\right]$ dan $B=\left[b_{i j}\right]$ adalah matriks partisi dengan jumlah partisi baris dan partisi kolom yang sama, dan partisi yang bersesuaian mempunyai ukuran yang sama. Maka penjumlahan partisi matriks yang bersesuaian dari $A$ dan $B$ juga menjumlahkan elemen-elemen yang bersesuaian dari $A$ dan $B$, dan perkalian tiap partisi dari $A$ dengan skalar $k$ akan mengalikan tiap elemen dari $A$ dengan $k$.

Contoh 2.8. Misalkan

$$
A=\left[\begin{array}{ll}
A_{11} & A_{12} \\
A_{21} & A_{22}
\end{array}\right], \quad B=\left[\begin{array}{ll}
B_{11} & B_{12} \\
B_{21} & B_{22}
\end{array}\right] .
$$

Maka

$$
\begin{aligned}
A+B & =\left[\begin{array}{ll}
A_{11}+B_{11} & A_{12}+B_{12} \\
A_{21}+B_{21} & A_{22}+B_{22}
\end{array}\right], \\
A B & =\left[\begin{array}{ll}
A_{11} B_{11}+A_{12} B_{21} & A_{11} B_{12}+A_{12} B_{22} \\
A_{21} B_{11}+A_{22} B_{21} & A_{21} B_{12}+A_{22} B_{22}
\end{array}\right], \\
k A & =\left[\begin{array}{ll}
k A_{11} & k A_{12} \\
k A_{21} & k A_{22}
\end{array}\right] .
\end{aligned}
$$

Berikut adalah aturan transpos matriks yang dipartisi [5]. Misalkan matriks $A=\left[\begin{array}{ll}A_{11} & A_{12} \\ A_{21} & A_{22}\end{array}\right]$. Maka $A^{T}=\left[\begin{array}{ll}A_{11} & A_{12} \\ A_{21} & A_{22}\end{array}\right]^{T}=\left[\begin{array}{cc}A_{11}^{T} & A_{21}^{T} \\ A_{12}^{T} & A_{22}^{T}\end{array}\right]$.

\subsection{Invers Matriks}

Definisi 2.9. [1] Jika $A$ adalah matriks bujursangkar, dan jika terdapat matriks $B$ yang ukurannya sama sedemikian rupa sehingga $A B=B A=I$, maka $A$ disebut dapat dibalik (invertible) dan $B$ disebut sebagai invers (inverse) dari A. Jika matriks $B$ tidak dapat didefinisikan, maka $A$ dinyatakan sebagai matriks singular.

Teorema 2.10. [1] Jika $B$ dan $C$ keduanya adalah invers dari matriks $A$, maka

$$
B=C \text {. }
$$

Teorema 2.11. [1] Jika matriks $A$ dan $B$ adalah matrik yang dapat dibalik dengan ukuran yang sama, maka $A B$ dapat dibalik, dan

$$
(A B)^{-1}=B^{-1} A^{-1} \text {. }
$$

Teorema 2.12. [7] Jika A adalah matriks yang dapat dibalik, maka $A^{T}$ juga dapat dibalik dan

$$
\left(A^{T}\right)^{-1}=\left(A^{-1}\right)^{T} .
$$

Teorema berikut ini akan memberikan kriteria penting mengenai keterbalikan dalam konteks determinan. 
Teorema 2.13. [1] Suatu matriks bujur sangkar A dapat dibalik, jika dan hanya $j i k a \operatorname{det}(A) \neq 0$.

Definisi 2.14. [7] Misalkan A adalah matrik berukuran $m \times n$. Matriks $B$ dengan ukuran $n \times m$ dikatakan invers kiri dari $A$ jika $B A=I_{n}$ dan matriks $C$ dengan ukuran $n \times m$ dikatakan invers kanan dari $A$ jika $A C=I_{m}$.

\subsection{Rank Matriks}

Definisi 2.15. [1] Misalkan $V$ adalah suatu himpunan takkosong dari objek-objek sebarang, dimana dua operasinya didefinisikan, yaitu penjumlahan dan perkalian dengan skalar (bilangan). Operasi penjumlahan dapat diartikan sebagai suatu aturan yang mengasosiasikan setiap pasang objek $\boldsymbol{u}$ dan $\boldsymbol{v}$ pada $V$ dengan suatu objek $\boldsymbol{u}+\boldsymbol{v}$, yang disebut jumlah dari $\boldsymbol{u}$ dan $\boldsymbol{v}$. Operasi perkalian skalar, dapat diartikan sebagai suatu aturan yang mengasosiasikan setiap skalar $k$ dan setiap objek $\boldsymbol{u}$ pada $V$ dengan suatu objek $k \boldsymbol{u}$, yang disebut kelipatan skalar dari $\boldsymbol{u}$ oleh $k$. jika aksiomaaksioma berikut dipenuhi oleh semua objek pada $\boldsymbol{u}, \boldsymbol{v}, \boldsymbol{w}$ pada $V$ dan senua skalar $k$ dan $l$, maka $V$ disebut sebagai ruang vektor dan objek-objek pada $V$ disebut sebagai vektor.

(1) Jika $\boldsymbol{u}$ dan $\boldsymbol{v}$ adalah objek-objek pada $V$, maka $u+v$ berada pada $V$.

(2) $\boldsymbol{u}+\boldsymbol{v}=\boldsymbol{v}+\boldsymbol{u}$.

(3) $\boldsymbol{u}+(\boldsymbol{v}+\boldsymbol{w})=(\boldsymbol{u}+\boldsymbol{v})+\boldsymbol{w}$.

(4) Di dalam $V$ terdapat suatu objek 0 , yang disebut vektor nol untuk $V$, sedemikian rupa sehingga $\boldsymbol{O}+\boldsymbol{u}=\boldsymbol{u}+\boldsymbol{O}$ untuk semua $\boldsymbol{u}$ pada $V$.

(5) Untuk setiap $\boldsymbol{u}$ pada $V$, terdapat suatu objek $-\boldsymbol{u}$ pada $V$, yang disebut sebagai negatif dari $\boldsymbol{u}$, sedemikian rupa sehingga $\boldsymbol{u}+(-\boldsymbol{u})=(-\boldsymbol{u})+\boldsymbol{u}=\boldsymbol{u}+\boldsymbol{v}=\boldsymbol{v}+\boldsymbol{O}$.

(6) Jika $k$ adalah skalar sebarang dan $\boldsymbol{u}$ adalah objek sebarang pada $V$, maka ku berada pada $V$.

(7) $k(\boldsymbol{u}+\boldsymbol{v})=k \boldsymbol{u}+k \boldsymbol{v}$.

(8) $(k+l) \boldsymbol{u}=k \boldsymbol{u}+l \boldsymbol{u}$.

(9) $k(l \boldsymbol{u})=(k l)(\boldsymbol{u})$.

(10) $1 \boldsymbol{u}=\boldsymbol{u}$.

Definisi 2.16. [1] Suatu subhimpunan $W$ dari suatu vektor $V$ disebut sub-ruang dari $V$ jika $W$ itu sendiri merupakan suatu ruang vektor dibawah penjumlahan dan perkalian skalar yang didefinisikan pada $V$.

Definisi 2.17. [1] Suatu vektor $\boldsymbol{w}$ disebut kombinasi linear dari vektor-vektor $v_{1}$, $v_{2}, \cdots, v_{r}$ jika dapat dinyatakan dalam bentuk

$$
w=k_{1} v_{1}+k_{2} v_{2}+\cdots+k_{r} v_{r}
$$

di mana $k_{1}, k_{2}, \cdots, k_{r}$ adalah skalar.

Definisi 2.18. [1] Jika $S=\left\{v_{1}, v_{2}, \cdots, v_{r}\right\}$ adalah suatu himpunan vektor-vektor pada suatu ruang vektor $V$, maka subruang $W$ dari $V$ yang terdiri dari semua kombinasi linear vektor-vektor pada $S$ disebut sebagai ruang yang direntang oleh 
$v_{1}, v_{2}, \cdots, v_{r}$ dan vektor-vektor $v_{1}, v_{2}, \cdots, v_{r}$ merentang $W$. Dapat ditulis sebagai $W=\operatorname{rentang}(S)$ atau $W=$ rentang $\left\{v_{1}, v_{2}, \cdots, v_{r}\right\}$.

Definisi 2.19. [1] Jika $S=\left\{v_{1}, v_{2}, \cdots, v_{r}\right\}$ adalah himpunan tak kosong vektorvektor, maka persamaan vektor

$$
k_{1} v_{1}+k_{2} v_{2}+\cdots+k_{r} v_{r}=0
$$

memiliki paling tidak satu solusi, yaitu

$$
k_{1}=0, k_{2}=0, \cdots, k_{r}=0
$$

Jika ini satu-satunya solusi, maka $S$ disebut sebagai himpunan bebas linear. Jika terdapat solusi lain, maka $S$ disebut sebagai himpunan tidak bebas linear.

Definisi 2.20. [7] Jika $A \in \mathbb{C}^{m \times n}$, didefinisikan ruang kolom dari $A$ ditulis $\operatorname{Col}(A)$ adalah subruang dari $\mathbb{C}^{m}$ yang dibangun oleh vektor-vektor kolom dari $A$.

Definisi 2.21. [7] Misal $A \in \mathbb{C}^{m \times n}$, didefinisikan ruang baris dari $A$ ditulis $\operatorname{Row}(A)$ adalah subruang dari $\mathbb{C}^{n}$ yang dibangun oleh vektor-vektor baris dari $A$.

Definisi 2.22. [1] Jika $V$ adalah suatu ruang vektor sebarang dan $S=$ $\left\{v_{1}, v_{2}, \cdots, v_{n}\right\}$ adalah suatu himpunan vektor-vektor pada $V$, maka $S$ disebut suatu basis untuk $V$ jika dua syarat berikut terpenuhi :

(1) $S$ bebas linear.

(2) $S$ merentang $d i V$.

Teorema 2.23. [1] Operasi baris elementer tidak mengubah ruang baris suatu matriks.

Teorema 2.24. [1] Misalkan A dan B adalah matriks-matriks yang ekivalen baris. Maka :

(a.) Suatu himpunan vektor-vektor kolom dari A tertentu adalah bebas linear jika dan hanya jika vektor-vektor kolom yang bersesuaian dari B adalah bebas linear.

(b.) Suatu himpunan vektor-vektor kolom dari A tertentu membentuk suatu basis untuk ruang kolom dari A jika dan hanya jika vektor-vektor kolom yang bersesuaian dari $B$ membentuk suatu basis untuk ruang kolom dari B.

Teorema 2.25. [1] Jika suatu matriks $R$ berada dalam bentuk eselon baris, maka vektor-vektor baris dengan satu utama (yaitu vektor-vektor baris taknol) membentuk suatu basis untuk ruang baris dari $R$, dan vektor-vektor kolom dengan satu utama dari vektor-vektor baris membentuk suatu basis untuk ruang kolom dari $R$

Definisi 2.26. [1] Dimensi dari ruang vektor $V$ yang berdimensi terhingga, dinotasikan dengan $\operatorname{dim}(V)$, didefinisikan sebagai banyaknya vektor-vektor pada suatu basis untuk V. Selain itu, ruang vektor nol didefinisikan berdimensi nol.

Definisi 2.27. [1] Dimensi dari ruang baris dan ruang kolom dari suatu matriks $A$ disebut rank dari $A$ dan dinyatakan sebagai $\operatorname{rank}(A)$. 
Teorema 2.28. [1] Jika $A$ adalah suatu matriks sebarang, maka $\operatorname{rank}(A)=$ $\operatorname{rank}\left(A^{T}\right)$.

Teorema 2.29. [3] Jika $A$ adalah sebarang matriks, maka rank(A) sama dengan banyaknya baris taknol dalam bentuk eselon baris tereduksi matriks $A$.

\subsection{Matriks Definit Positif}

Persamaan linear dengan $n$ variabel $x_{1}, x_{2}, \cdots, x_{n}$ dapat dinyatakan dalam bentuk

$$
a_{1} x_{1}+a_{2} x_{2}+\cdots+a_{n} x_{n}=b
$$

dimana $a_{1}, a_{2}, \cdots, a_{n}$ dan $b$ adalah konstanta real yang dinamakan bentuk linear. Dalam bentuk linear semua variabel berpangkat satu, dan tidak ada hasil kali variabel pada persamaan (2.1). Dalam bentuk kuadrat suku-sukunya adalah kuadrat dari variabel atau hasil kali dua variabel. Bentuk kuadrat dalam dua variabel $x$ dan $y$ dapat ditulis sebagai

$$
a x^{2}+2 b x y+c y^{2}=\left[\begin{array}{ll}
x & y
\end{array}\right]\left[\begin{array}{ll}
a & b \\
b & c
\end{array}\right]\left[\begin{array}{l}
x \\
y
\end{array}\right]
$$

Bentuk kuadrat yang lebih umum didefinisikan sebagai berikut.

Definisi 2.30. [1] Bentuk kuadrat dari $x_{1}, x_{2}, \cdots, x_{n}$ dapat ditulis dalam bentuk

$$
\left(\begin{array}{llll}
x_{1} x_{2} & \cdots & x_{n}
\end{array}\right) A\left(\begin{array}{c}
x_{1} \\
x_{2} \\
\vdots \\
x_{n}
\end{array}\right)
$$

dengan $A$ adalah matriks $n \times n$.

Jika dimisalkan

$$
x=\left(\begin{array}{c}
x_{1} \\
x_{2} \\
\vdots \\
x_{n}
\end{array}\right),
$$

maka (2.3) menjadi

$$
x^{T} A x
$$

Definisi 2.31. [1] Bentuk kuadrat $x^{T} A x$ disebut definit positif jika $x^{T} A x>0$ untuk semua $x \neq \boldsymbol{O}$.

Lema 2.32. [4] Sebarang matriks definit positif adalah matriks nonsingular.

Bukti. Misalkan A adalah matriks singular, terdapat vektor taknol sedemikian sehingga $A x=0$. Oleh karena itu $x^{T} A x=0$ dan $A$ tidak bisa menjadi matriks definit positif. 


\subsection{Pengertian Invers Moore-Penrose}

Invers Moore-Penrose sering juga dikenal dengan pseudoinvers. Berikut adalah definisi invers Moore-Penrose.

Definisi 2.33. [2] Misalkan $A \in \mathbb{C}^{m \times n}$. Matriks $A$ dikatakan mempunyai invers Moore-Penrose jika terdapat matriks $X \in \mathbb{C}^{n \times m}$ sedemikian sehingga

(1) $A X A=A$.

(2) $X A X=X$.

(3) $(A X)^{*}=A X$.

(4) $(X A)^{*}=X A$.

Matriks $X$ pada definisi di atas ditulis sebagai $A^{+}$.

\subsection{Faktorisasi Full Rank}

Definisi 2.34. [7] Misalkan $A \in \mathbb{C}_{r}^{m \times n}$ dengan $r>0$. Jika terdapat $F \in \mathbb{C}_{r}^{m \times r}$ dan $G \in \mathbb{C}_{r}^{r \times n}$ sedemikian sehingga $A=F G$, maka $A$ dikatakan memiliki faktorisasi full rank.

Teorema 2.35. [8] Misalkan $A \in \mathbb{C}_{r}^{m \times n}$ dengan $\operatorname{rank}(A)>0$ dan $A=F G$ adalah faktorisasi full rank dari A. Maka

(1) $F^{+}=\left(F^{*} F\right)^{-1} F^{*}$.

(2) $F^{+} F=I$ dengan $I$ matriks identitas $r \times r$.

(3) $G^{+}=G^{*}\left(G G^{*}\right)^{-1}$.

(4) $G G^{+}=I$ dengan $I$ matriks identitas $r \times r$.

(5) $A^{+}=G^{+} F^{+}$.

Bukti. Misalkan $A \in \mathbb{C}_{r}^{m \times n}$ dengan $\operatorname{rank}(A)>0$ dan $A=F G$ adalah faktorisasi full rank dari $A$. Dengan menggunakan keempat persamaan Penrose pada Definisi (2.9), diperoleh

(1) $F F^{+} F=F\left(F^{*} F\right)^{-1}\left(F^{*} F\right)=F I=F$.

(2) $F^{+} F F^{+}=\left(F^{*} F\right)^{-1}\left(F^{*} F\right)\left(F^{*} F\right)^{-1} F^{*}=I\left(F^{*} F\right)^{-1} F^{*}=F^{+}$.

(3) $\left(F F^{+}\right)^{*}=F^{* *}\left(F^{*} F\right)^{-1} F^{*}=F\left(F^{*} F\right)^{-1} F^{*}=F F^{+}$.

(4) $\left(F^{+} F\right)=\left(F^{*} F\right)^{-1}\left(F^{*} F\right)=I$.

\section{Penghitungan Invers Moore-Penrose dengan Metode Ben Noble}

Penghitungan invers Moore-Penrose dengan metode Ben Noble menggunakan partisi matriks. Berikut ini langkah-langkah menghitung invers Moore-Penrose.

Misalkan $A$ adalah matriks berukuran $m \times n$ dengan $\operatorname{rank}(A)=r$. Matriks $A$ dipartisi dalam bentuk

$$
A=\left[\begin{array}{ll}
A_{11} & A_{12} \\
A_{21} & A_{22}
\end{array}\right]
$$


dengan $A_{11}$ berukuran $r \times r$, dan matriks $A_{11}$ adalah matriks non-singular. Jika matriks $A_{11}$ adalah singular, maka matriks $A$ dapat dikalikan dengan matriks permutasi untuk merubah baris dan kolom sehingga matriks $A_{11}$ menjadi matriks nonsingular. Misalkan $T$ dan $S$ adalah matriks permutasi, maka

$$
T A S=\left[\begin{array}{ll}
A_{11} & A_{12} \\
A_{21} & A_{22}
\end{array}\right] .
$$

Karena rank $A$ adalah $r, m-r$ baris terakhir adalah kombinasi linear dari $r$ pertama, sehingga terdapat matriks $P_{(m-r) \times r}$ yang memenuhi

$$
A_{21}=P A_{11} \text { dan } A_{22}=P A_{12},
$$

dan terdapat matriks $Q_{r \times(n-r)}$ yang memenuhi

$$
A_{12}=A_{11} Q \text { dan } A_{22}=A_{21} Q
$$

sehingga

$$
P=A_{21} A_{11}^{-1} \text { dan } Q=A_{11}^{-1} A_{12}
$$

dengan mengkombinasikan persamaan kedua dalam (3.3) dan persamaan pertama dalam (3.4) diperoleh

$$
A_{22}=P A_{11} Q
$$

Oleh karena itu matriks $A$ dapat ditulis dalam bentuk

$$
A=T^{T}\left[\begin{array}{c}
I \\
P
\end{array}\right] A_{11}\left[\begin{array}{ll}
I & Q
\end{array}\right] S^{T},
$$

dengan $I$ adalah matriks identitas berukuran $r \times r$.

Berdasarkan Definisi (2.34) diperoleh

$$
F=T^{T}\left[\begin{array}{c}
I \\
P
\end{array}\right] A_{11}, \operatorname{dan} G=\left[\begin{array}{ll}
I & Q
\end{array}\right] S^{T} .
$$

Teorema 3.1. [6] Misalkan $A \in \mathbb{C}_{r}^{m \times n}$ dipartisi ke dalam persamaan (3.7), maka invers Moore-Penrose matriks $A$ adalah

$$
\begin{aligned}
& A^{+}=S\left[\begin{array}{c}
I \\
Q^{*}
\end{array}\right]\left[I+Q Q^{*}\right]^{-1} A_{11}^{-1}\left[I+P^{*} P\right]^{-1}\left[I P^{*} P\right] T, \\
& \text { dengan } Q \in \mathbb{C}^{r \times(n-r)} \text { dan } P \in \mathbb{C}^{(m-r) \times r} .
\end{aligned}
$$

Bukti. Oleh karena

$$
A=T^{T}\left[\begin{array}{ll}
A_{11} & A_{12} \\
A_{21} & A_{22}
\end{array}\right] S^{T}
$$

dapat dikenakan faktorisasi full rank dengan faktorisasi full rank dari $A$ adalah

$$
F=T^{T}\left[\begin{array}{c}
I \\
P
\end{array}\right] A_{11} \operatorname{dan} G=\left[\begin{array}{ll}
I & Q
\end{array}\right] S^{T},
$$


sehingga diperoleh

$$
A^{+}=S\left[\begin{array}{c}
I \\
Q^{*}
\end{array}\right]\left[I+Q Q^{*}\right]^{-1} A_{11}^{-1}\left[I+P^{*} P\right]^{-1}\left[I P^{*} P\right] T
$$

dengan $Q \in \mathbb{C}^{r \times(n-r)}$ dan $P \in \mathbb{C}^{(m-r) \times r}$.

Persamaan (3.10) dapat digunakan mengingat matriks $\left[I+P^{*} P\right]$ adalah definit-positif karena

$$
\mathbf{u}^{*}\left[I+P^{*} P\right] \mathbf{u}=\mathbf{u}^{*} \mathbf{u}+[P \mathbf{u}]^{*}[P \mathbf{u}]>0 \quad \text { untuk } \mathbf{u} \neq \mathbf{0} .
$$

Berdasarkan Lemma (2.32), matriks $\left[I+P^{*} P\right]$ adalah matriks non-singular.

Akibat 3.2. Jika $A=\left[\begin{array}{cc}A_{11} & \mathbb{O} \\ \mathbb{O} & \mathbb{O}\end{array}\right]$ dengan $\operatorname{det}\left(A_{11}\right) \neq 0$ dan $\nvdash$ adalah matriks nol maka

$$
A^{+}=\left[\begin{array}{cc}
A_{11}^{-1} & \mathbb{O} \\
\mathbb{O} & \mathbb{O}
\end{array}\right]
$$

Berikut adalah akibat berdasarkan Teorema 3.1.

Akibat 3.3. Jika $A=\left[\begin{array}{cc}A_{11} & 0 \\ 0 & 0\end{array}\right]$ dengan $\operatorname{det}\left(A_{11}\right) \neq 0$ maka

$$
A^{+}=\left[\begin{array}{cc}
A_{11}^{-1} & 0 \\
0 & 0
\end{array}\right] \text {. }
$$

\subsection{Algoritma Penghitungan Invers Moore-Penrose}

(1) Menentukan $\operatorname{rank}(A)$ dengan melakukan OBE terhadap matriks $A$ sehingga membentuk matriks eselon baris tereduksi.

(2) Misalkan $\operatorname{rank}(A)>0$, matriks $A$ dipartisi ke bentuk

$$
A=\left[\begin{array}{ll}
A_{11} & A_{12} \\
A_{21} & A_{22}
\end{array}\right]
$$

dimana matriks $A_{11}$ berukuran $r \times r$.

(3) Jika matriks $A_{11}$ singular, maka kalikan matriks $A$ dengan matriks permutasi $T$ dan $S$ sehingga matriks $A_{11}$ non-singular.

$$
T A S=\left[\begin{array}{ll}
A_{11} & A_{12} \\
A_{21} & A_{22}
\end{array}\right]
$$

(4) Menentukan invers matriks $A_{11}$

(5) Menentukan matriks $P \in \mathbb{C}^{r \times(n-r)}$ dengan rumus $P=A_{21} A_{11}^{-1}$.

(6) Menentukan matriks $Q \in \mathbb{C}^{(m-r) \times r}$ dengan rumus $Q=A_{11}^{-1} A_{12}$.

(7) Hitung Invers Moore-Penrose dengan rumus

$$
A^{+}=S\left[\begin{array}{c}
I \\
Q^{*}
\end{array}\right]\left[I+Q Q^{*}\right]^{-1}\left[A_{11}\right]^{-1}\left[I+P^{*} P\right]^{-1}\left[I P^{*}\right] T
$$




\section{Kesimpulan}

Berdasarkan pembahasan tentang penghitungan invers Moore-Penrose dari matriks $A \in \mathbb{C}_{r}^{m \times n}$ dengan $\operatorname{rank}(A)>0$ menggunakan metode Ben-Noble, dapat disimpulkan bahwa metode ini menggunakan partisi matriks dan faktorisasi full rank. Berikut adalah langkah menentukan invers Moore Penrose dari matriks $A \in \mathbb{C}_{r}^{m \times n}$.

1. Tentukan $\operatorname{rank}(\mathrm{A})$, kemudian partisi matriks $A$ menjadi

$$
A=\left[\begin{array}{ll}
A_{11} & A_{12} \\
A_{21} & A_{22}
\end{array}\right],
$$

dengan $A_{11}$ matriks non-singular berukuran $r \times r$.

2. Jika matriks $A_{11}$ singular, maka kalikan matriks $A$ dengan matriks permutasi $T$ dan $S$ sehingga matriks $A_{11}$ non-singular.

$$
T A S=\left[\begin{array}{ll}
A_{11} & A_{12} \\
A_{21} & A_{22}
\end{array}\right] .
$$

3. Tentukan invers matriks $A_{11}$.

4. Tentukan matriks $P$ dan $Q$ menggunakan persamaan (3.5).

5. Hitung invers Moore-Penrose matriks $A$ dengan persamaan

$$
A^{+}=\left[\begin{array}{c}
I \\
Q^{*}
\end{array}\right]\left[I+Q Q^{*}\right]^{-1}\left[A_{11}\right]^{-1}\left[I+P^{*} P\right]^{-1}\left[I P^{*}\right] .
$$

\section{Daftar Pustaka}

[1] Anton, H. 2005. Aljabar Linear Elementer. Edisi Kelima. Erlangga. Jakarta

[2] Ben-Israel dan Thomas N.E Greville. 2003. Generalized Inverses Theory and Applications. Springger Verlag, New York.

[3] Broida, J.G dan Williamson, S.G. 2012. Comprehensive Introduction To Linear Algebra. Creative Commons

[4] Cormen, T.H dkk. 2009 Introduction To Algorithms. Massachusetts Institute of Technology. London

[5] Laub. A 2012. Matrix Analysis. SIAM.

[6] Noble, B. 1966. A Method For Computing The Generalized Inverses of a Matrix. Vol 3, No.44. SIAM

[7] Piziak, R dan P.L. Odel. 2007. Matrix Theory From Generalized Inverses to Jordan Form. Taylor dan Francis, Canada

[8] Piziak, R dan P.L. Odel. 1999. Full Rank Factorization of Matrices. Mathematics Magazine. Vol 72. No $3: 193-201$ 